Article

\title{
An Adaptive Frequency Strategy for Variable Speed Wind Turbines: Application to High Wind Integration Into Power Systems
}

\author{
Ana Fernández-Guillamón 1,*iD), Jorge Villena-Lapaz ${ }^{2}$, Antonio Vigueras-Rodríguez $^{3}$ (D), \\ Tania García-Sánchez ${ }^{4}$ and Ángel Molina-García 1 (D) \\ 1 Department of Electrical Engineering, Universidad Politécnica de Cartagena, 30202 Cartagena, Spain; \\ angel.molina@upct.es \\ 2 Alberta Electric System Operator, Calgary, AB T2P 0L4, Canada; jorge.villena@aeso.ca \\ 3 Department of Civil Engineering, Universidad Politécnica de Cartagena, 30203 Cartagena, Spain; \\ avigueras.rodriguez@upct.es \\ 4 Department of Electrical Engineering, Universidad Politécnica de Valencia, 46022 Valencia, Spain; \\ tagarsan@die.upv.es \\ * Correspondence: ana.fernandez@upct.es; Tel.: +34-968-325357
}

Received: 10 May 2018; Accepted: 29 May 2018; Published: 4 June 2018

\begin{abstract}
This paper presents a new frequency controller for variable speed wind turbines connected to the grid under power imbalance conditions. It is based on the fast power reserve emulation technique, having two different operation modes: overproduction and recovery mode. In the first mode, the active power provided by wind turbines is set over the mechanical power, reducing their rotational speed. This overproduction power is estimated according to the frequency excursion. In the second mode, the active power is established under the mechanical power to recover the initial rotational speed through a smooth trajectory. The power system considered for simulation purposes includes thermal, hydro-power and wind-power plants. The controller proposed has been evaluated under different mix-generation scenarios implemented in Matlab/Simulink. Extensive results and comparison to previous proposals are also included in the paper.
\end{abstract}

Keywords: frequency control; wind energy; renewable energy sources integration; power system stability

\section{Introduction}

During the last decade, and due to aspects such as climate change, energy dependence, fossil resource scarcity and the increasing costs of nuclear power [1], most developed countries have promoted large-scale integration of Renewable Energy Sources (RES), mainly wind and PV power plants [2]. This relevant integration of RES has raised important concerns in terms of grid stability and reliability, mainly due to: (i) the nature of RES power variation [3] as well as the uncertainty in the privately-owned renewable generators that puts the generation-load balance at risk [4]; (ii) the reduction of the total system inertia by the decoupling between rotor mechanical speed and grid frequency [5], or even the absence of rotating machines [6]. As the system inertia decreases, an increase of primary frequency control (PFC) reserves is needed [7]. Traditionally, PFC reserves are provided by synchronous generators [8], as depicted in Figure 1a. Under power imbalance conditions, PFC reserves from conventional generation are traditionally released to compensate the disturbance and recover the rate grid frequency. If these reserves cannot compensate for the mismatch, it could cause a sharp decrease of the system frequency [9]. With the relevant penetration of wind power plants, some proportional capacity of the system reserves must be provided by them $[7,10]$ see Figure $1 \mathrm{~b}$. 
Additional reserves can be then provided by renewables, reducing the primary reserves from conventional generation units and providing enhanced solutions for weak and/or isolated power systems $[9,11]$. Under this scenario of high RES penetration, transmission system operators have required that not only conventional utilities contribute to ancillary services [12], but also renewables, especially wind power plants [13]. Indeed, [14] affirms that the participation of the wind power plants in the ancillary services such as grid frequency control becomes inevitable. For this reason, frequency control strategies are being developed to effectively integrate Variable Speed Wind Turbines (VSWTs) into the grid, in order to replace conventional power plants by maintaining a secure power system operation [15]. Most of them are based on 'hidden inertia emulation', in order to enhance the inertia response of VSWTs $[16,17]$. A classification for different control strategies based on principles for inertia emulation concept can be found in [18]. One of the possible solutions to overcome this is called fast power reserve emulation. It is based on supplying the kinetic energy stored in the rotating masses to the grid as an additional active power, being afterwards recovered through an under-production period (recovery). Overproduction is defined in the specific literature over the electrical pre-event power reference [19-24] and the overproduction power is considered as constant and independent from the frequency excursion severity [21-23]. Other proposals define the time that the wind power plant must be overproducing independently from the event [19-22] or consider that it should last until the wind turbine achieves its minimum speed limit [23]. Moreover, the transition from overproduction to recovery is defined as an abrupt drop in the active generated power by VSWTs $[21,23,24]$ or as a constant slope $[19,22]$. A different strategy is described in [20], where the VSWTs of the wind power plant are designed to recover at different times, avoiding 'synchronization'. Most contributions consider a low wind energy integration for simulations, between 10 and $20 \%[19,20,22]$, and only recent contributions analyze penetration level scenarios up to $40 \%$ [10]. However, the renewable share is currently over $20 \%$ in different power systems. Actually, some countries have already experienced instantaneous penetration higher than 50\% (i.e., Spain, Portugal, Ireland, Germany and Denmark) [25]. Subsequently, scenarios with a very relevant integration of wind energy should be considered and evaluated.

To overcome these drawbacks, and with the aim of improving the frequency response of power systems with massive wind energy penetration, this paper describes and evaluates an alternative fast power reserve emulation controller. The main contributions of this paper are summarized as follows:

- The active power provided by VSWTs during the overproduction operation mode is defined over the mechanical power instead of the pre-event electrical power. Such mechanical power varies with the rotational speed instead of keeping constant as the former one. Moreover, the overproduction power is estimated according to the frequency excursion, being thus an 'adaptive' overproduction strategy.

- The active power provided by VSWTs during the recovery operation mode is defined below the mechanical power to recover the rotational energy delivered in the overproduction mode. It is defined as a parabolic trajectory until the rotational speed reaches the maximum power tracking curve. Thereafter, that curve is followed. Because of that, it is considered as a 'smooth' recovery period.

- The control strategy proposed has been tested under different scenarios, considering a maximum wind energy integration of $45 \%$. In all the scenarios, the proposed solution reduces significantly the grid frequency deviations under power imbalance conditions.

The rest of the paper is organized as follows: in Section 2 the proposed frequency controller for VSWTs is described and compared to previous approaches. The power system and the different scenarios needed to assess the proposed control are discussed in Section 3. Simulation results are given in Section 4. Finally, Section 5 gives the conclusions. 


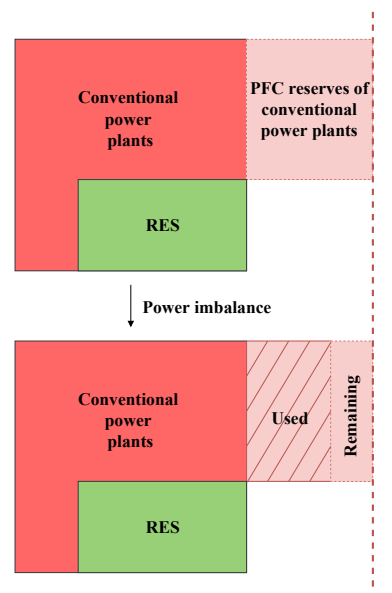

(a)

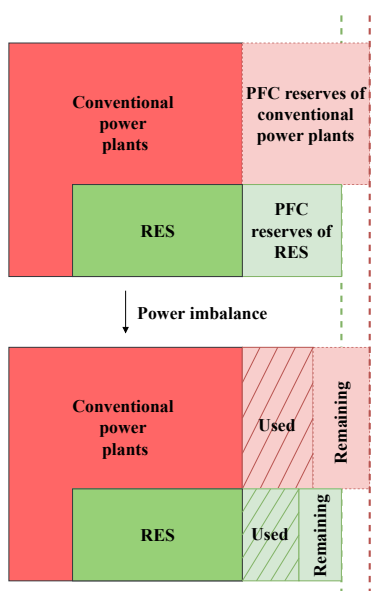

(b)

Figure 1. Change in primary frequency control (PFC) reserves from current to future power systems: (a) Current situation; (b) Future situation.

\section{Proposed Frequency Strategy for Wind Turbines}

A new frequency control strategy for VSWTs is presented in this work. It is based on supplying the kinetic energy stored in the rotating masses of the VSWT in order to enhance its inertial response. Three different operation modes are defined: normal operation, overproduction mode and recovery mode. Each mode sets a different commanded active power $P_{c m d}$ to restore the grid frequency after a power imbalance. In Figure 2, a general scheme of the proposed VSWTs frequency controller is shown.

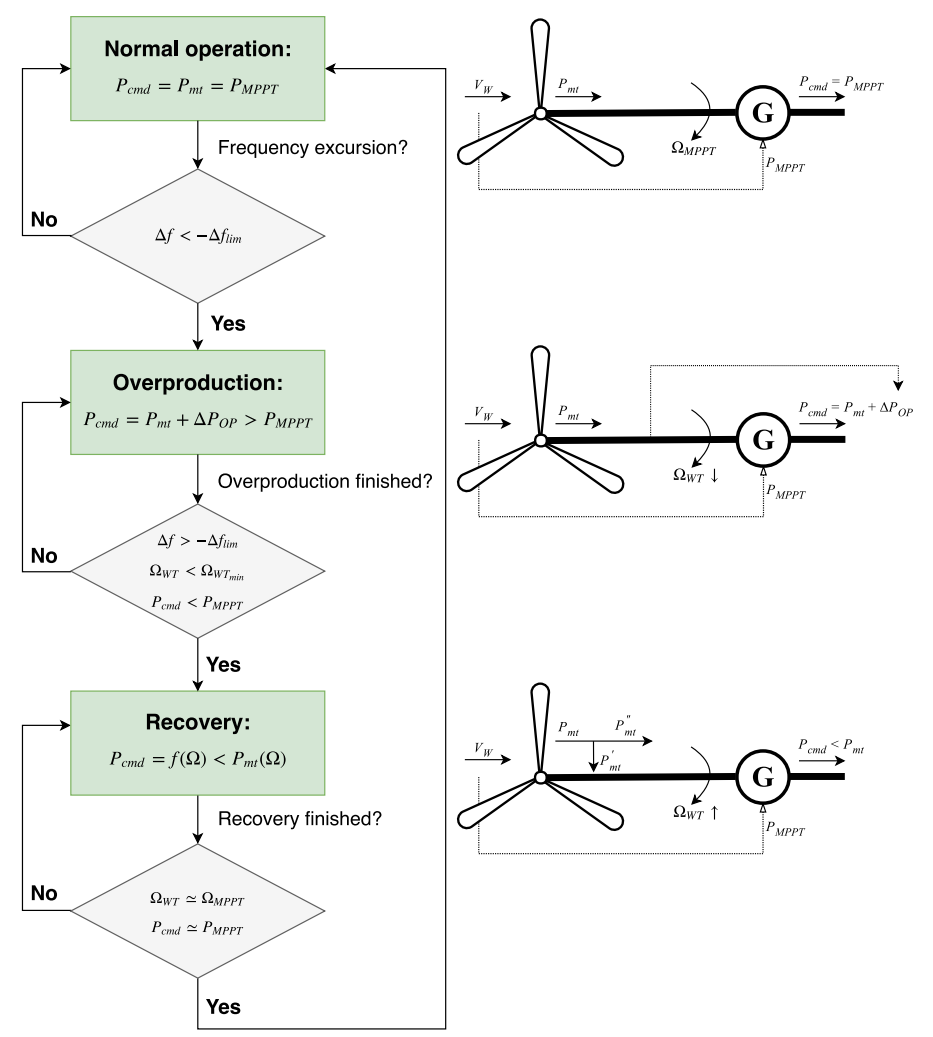

Figure 2. Scheme of the proposed Variable Speed Wind Turbines (VSWTs) frequency controller. 


\subsection{Normal Operation Mode}

The VSWTs operate at a certain point $P_{c m d}$ according to their mechanical curve $P_{m t}\left(\Omega_{W T}\right)$. The power controller compensates any change in the rotational speed $\Omega_{W T}$ or in the wind speed $V_{W}$, tracking the maximum available active power for a current wind speed $P_{M P P T}\left(V_{W}\right)$.

Under power imbalance conditions, and assuming a power supply-side decreasing, a frequency (negative) deviation $\Delta f$ is suffered by the power system. The proposed frequency controller is then initialized through an adaptive overproduction strategy:

$$
\Delta f<-\Delta f_{\text {lim }} \rightarrow \text { Overproduction. }
$$

\subsection{Overproduction Operation Mode}

The active power provided by the VSWTs, $P_{c m d}$, involves the mechanical power $P_{m t}\left(\Omega_{W T}\right)$ obtained from the wind and an additional active power $\Delta P_{O P}$ taken from the rotational speed energy stored in the rotor, $P_{c m d}=P_{m t}\left(\Omega_{W T}\right)+\Delta P_{O P}$. The proposed strategy results in a rotational speed decreasing, and subsequently a reduction of the mechanical power provided by the blades. Regarding to the additional power $\Delta P_{O P}$, it is estimated proportionally to the frequency excursion evolution, see Figure 3, which gives an adaptive response depending on the frequency excursion severity and thus emulating PFC of conventional generation units $[26,27]$. This strategy gives a more realistic scenario, a smoother response and, additionally, provides a frequency response in line with conventional primary frequency performances. Previous approaches assume the overproduction as a constant value and independent on the frequency excursion [21-23]. Moreover, the overproduction mode defined in this work considers that mechanical power $P_{m t}$ depends on the rotational speed $P_{m t}\left(\Omega_{W T}\right)$, whereas most authors assumed that mechanical power was constant when rotational speed decreased [19-24]. This overproduction strategy remains active until the frequency excursion disappears, the rotational speed reaches a minimum allowed value, or the commanded power is lower than the maximum available active power.

$$
\Delta f>-\Delta f_{\text {lim }} \text { or } \Omega_{W T}<\Omega_{W T, \text { min }} \text { or } P_{c m d}<P_{M P P T}\left(\Omega_{M P P T}\right) \rightarrow \text { Recovery. }
$$

In previous contributions, the minimum rotational speed was considered as a constant value; i.e., $\Omega_{W T, \min }=0.7 \mathrm{pu}$ in [23]. Under this assumption, the rotational speed deviation interval, $\Delta \Omega$ depends on the initial rotational speed value $\Omega_{M P P T}$, giving different regulation ranges. To improve this solution, the minimum rotational speed is proposed to be determined according to the initial value $\Omega_{M P P T}$, being thus $\Omega_{W T \text {,min }}=0.7 \cdot \Omega_{M P P T}$. This way, $\Omega_{W T \text {, min }}$ is a function of $\Omega_{M P P T}$ and a $30 \%$ of rotational speed deviation is allowed. Figure 4a shows the corresponding $\Delta \Omega_{W T}=\Omega_{M P P T}-\Omega_{W T \text {,min }}$ differences depending on the wind speed values $V_{W}$ considering a fixed $\Omega_{W T, m i n}$. Figure $4 \mathrm{~b}$ depicts the proposed definition for $\Omega_{W T \text {, min }}$. In addition, Figure 5 compares the overproduction strategy discussed in [23] and the alternative approach proposed in this work.

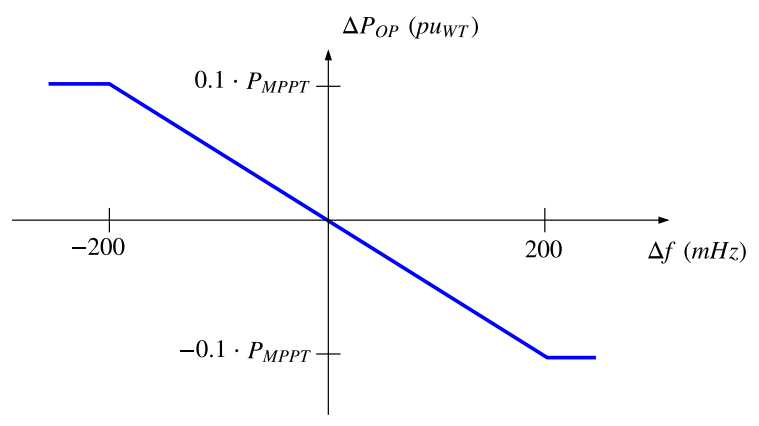

Figure 3. Proposed relationship between $\Delta P_{O P}$ and $\Delta f$ for VSWTs during overproduction. 


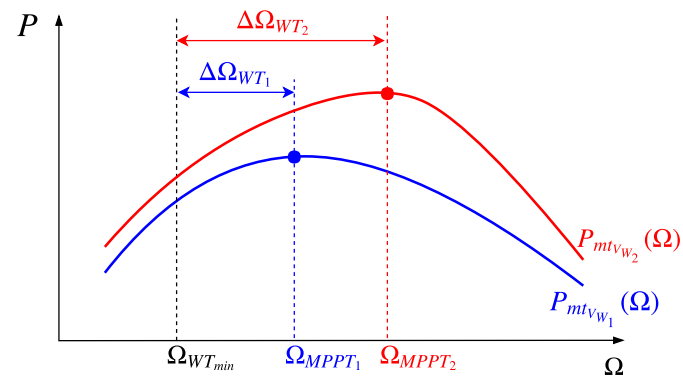

(a)

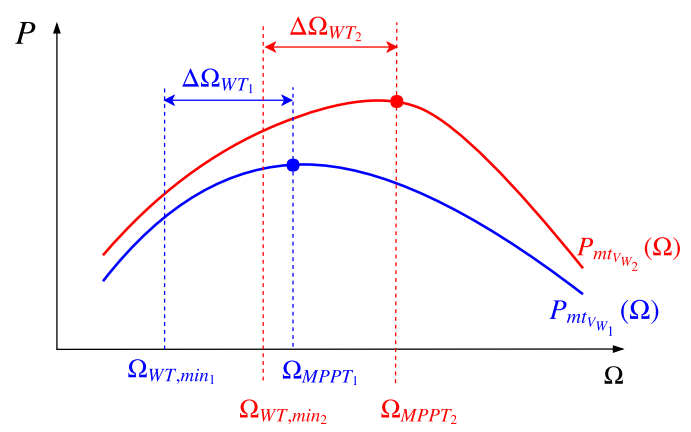

(b)

Figure 4. Comparison between overproduction operation modes. (a) $\Delta \Omega_{W T}$ for different wind speeds $V_{W}$, [23]; (b) Proposed $\Delta \Omega_{W T}$ for different wind speeds $V_{W}$.

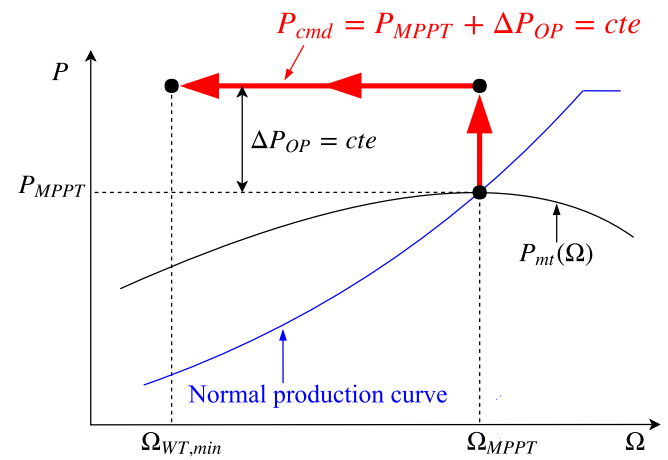

(a)

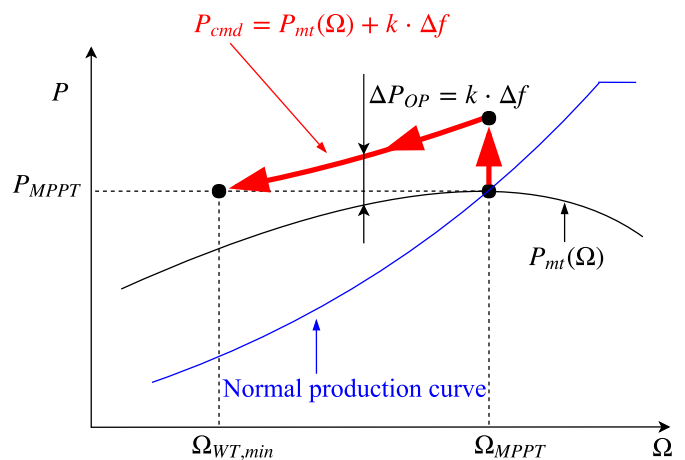

(b)

Figure 5. Comparison between overproduction operation modes; (a) Overproduction operation mode in [23]; (b) Overproduction operation mode proposed.

\subsection{Recovery Operation Mode}

After the overproduction period, a recovery operation mode is proposed to restore the rotational speed to the initial value $\Omega_{M P P T}$ and provide an optimal active power from the VSWTs. With the aim of minimizing undesirable frequency oscillations and abrupt changes from the supply-side, an alternative recovery strategy is defined and evaluated. This proposal is based on a parabolic smooth recovery strategy. Three points are considered to define this trajectory: (i) mechanical power at the minimum rotational speed achieved during the frequency excursion,

$$
P_{1}:\left(\Omega_{W T, \min }, P_{m t}\left(\Omega_{W T, \min }\right)\right) \text {. }
$$

(ii) mechanical power corresponding to the middle rotational speed deviation,

$$
P_{2}:\left(\Omega_{V}, P_{M P P T}\left(\Omega_{V}\right)\right),
$$

where $\Omega_{V}$ is $\Omega_{W T, \min }+0.5 \cdot \Delta \Omega$, and $\Delta \Omega$ is $\Omega_{M P P T}-\Omega_{W T \text {,min }}$. (iii) maximum mechanical power available according to the wind speed,

$$
P_{3}:\left(\Omega_{M P P T}, P_{M P P T}\left(\Omega_{M P P T}\right)\right) .
$$


The commanded power before achieving $P_{2}$ is determined according to $P_{c m d}=a \cdot \Omega_{W T}^{2}+b \cdot \Omega_{W T}+c$, where $a, b$ and $c$ can be estimated by considering the three mechanical power points aforementioned. Finally, the commanded power tracks the maximum power curve available according to the power wind speed curve: $P_{c m d}=P_{M P P T}\left(\Omega_{W T}\right)$. The normal operation mode is then recovered when either $\Omega_{M P P T}$ or $P_{M P P T}\left(\Omega_{M P P T}\right)$ are respectively achieved,

$$
\Omega_{W T} \simeq \Omega_{M P P T} \text { or } \quad P_{c m d} \simeq P_{M P P T}\left(\Omega_{M P P T}\right) \rightarrow \text { Normal operation. }
$$

In [23] the recovery period is defined as $P_{c m d}=P_{m t}-P_{a c c}$, being $P_{a c c}$ a constant underproduction power value. Under this assumption, the higher $P_{a c c}$, the faster the rotational speed recovers its optimal initial value $\Omega_{M P P T}$. Despite the fact that a value of $P_{a c c}=0.02 \mathrm{pu}$ was fixed, the fast and abrupt transition from overproduction to recovery operation mode may cause an additional and severe frequency oscillation. The recovery operation mode defined in this work determines the trajectory followed by the wind farm instead of fixing a certain underproduction power, $P_{a c c}$. In Figure 6, a comparison between the recovery mode proposed in [23] and the alternative strategy described in this work is depicted. Furthermore, the recovery operation mode has been improved by modifying $P_{2}$. The power in point $P_{2}$ is then defined in accordance to the differences between $P_{M P P T}\left(\Omega_{V}\right)$ and $P_{m t}\left(\Omega_{V}\right), P_{M P P T}\left(\Omega_{V}\right)+x \cdot\left(P_{m t}\left(\Omega_{V}\right)-P_{M P P T}\left(\Omega_{V}\right)\right)$, where $x$ has been considered as $0.25,0.50$ and 0.75 . When $P_{c m d}$ achieves $P_{2_{x}}$, the active power is above the curve of $P_{M P P T}$ proportionally to the difference between $P_{m t}\left(\Omega_{W T}\right)$ and $P_{M P P T}\left(\Omega_{W T}\right)$, providing an adaptive and smooth recovery response. In Figure 7 , the different proposals for the recovery operation mode are compared.

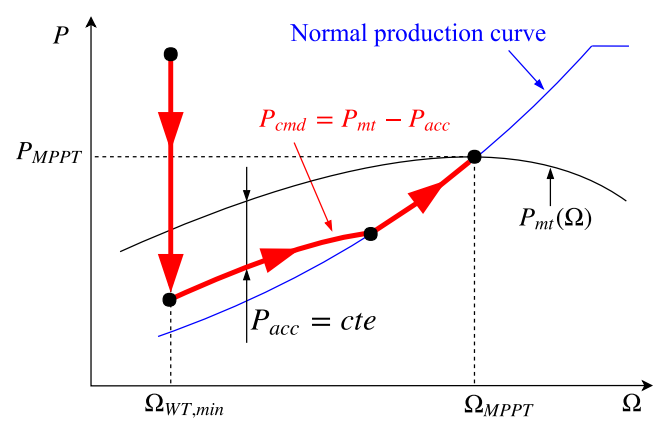

(a)

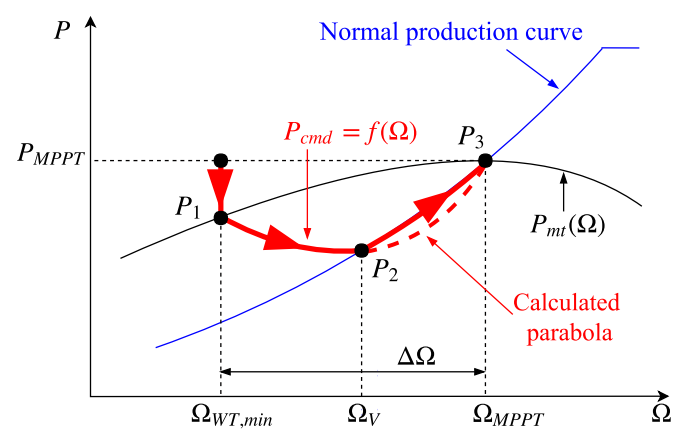

(b)

Figure 6. Comparison between recovery operation modes. (a) Recovery operation mode in [23]; (b) Recovery operation mode proposed.

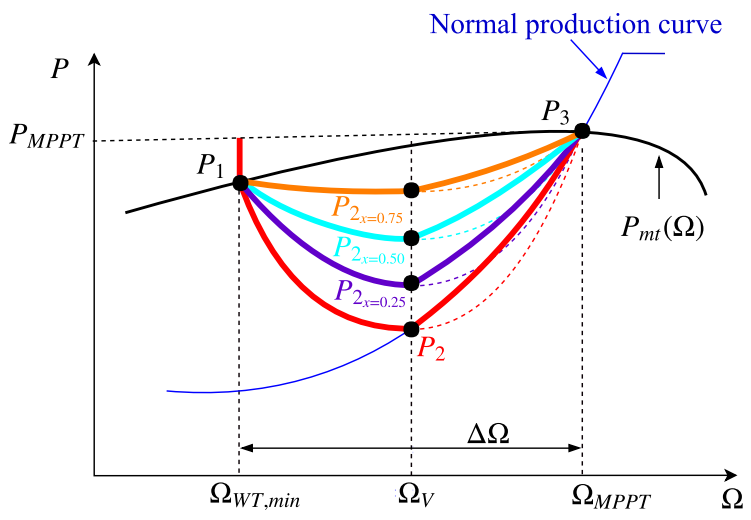

Figure 7. Different proposals for recovery operation mode. 
In Figure 8a, the control strategy proposed in [23] is shown. Figure 8b summarizes the new approach discussed in this work. Moreover, Figure 9 compares the VSWTs active power variations submitted to a frequency excursion, where $\Delta P_{W F}=P_{c m d}-P_{M P P T}\left(\Omega_{M P P T}\right)$. As can be seen, the proposed strategy offers a more adaptive and smoother power oscillation, which leads to reduce possible frequency oscillations due to abrupt imbalances.

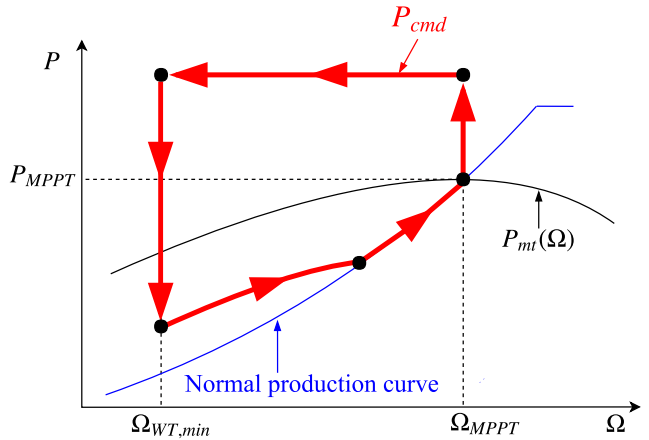

(a)

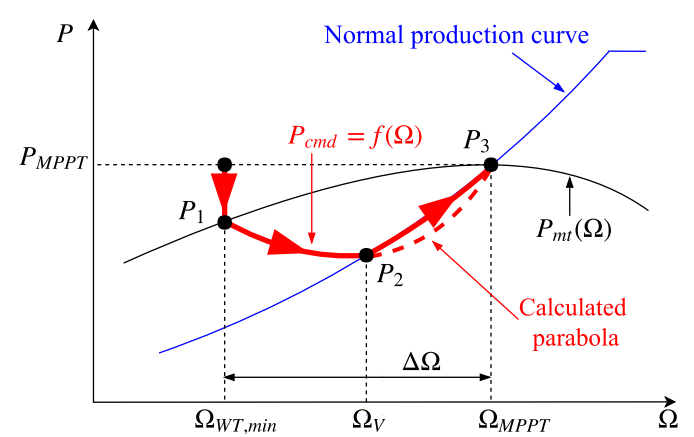

(b)

Figure 8. Comparison of frequency control strategies for VSWT. (a) Control strategy in [23]; (b) Adaptive and smooth proposed control strategy.

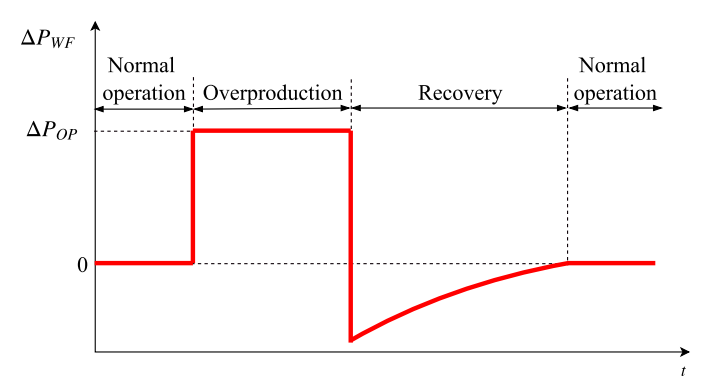

(a)

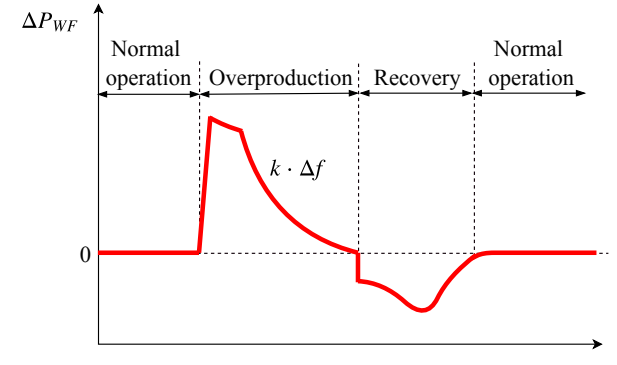

(b)

Figure 9. Additional active power of wind power plants: comparison of strategies. (a) $\Delta P_{W F}$ in [23]; (b) $\Delta P_{W F}$ proposed.

\section{Cases of Study}

\subsection{Power System Modeling}

From the supply-side, the power system considered for simulation purposes involve conventional generating units such as thermal and hydro-power plants, and wind power plants, Simulations have been carried out in Matlab/Simulink (2016 Student Suite Version, MathWorks, Natick, MA, USA). The total capacity of the power system is $1350 \mathrm{MW}$. Simplified governor-based models have been used to simulate both thermal and hydro-power plants according to [26], see Figure 10a,b. In Appendix A, the different values of the parameters of the block diagrams are presented. To simulate the wind power plant, an equivalent generator with $n$-times the nominal power of one wind turbine is assumed [28], being $n$ the total number of turbines $[29,30]$. The frequency controller introduced in Section 2 is added to the wind power plant model in order to provide frequency response under power imbalances. With those considerations, the block diagram of the VSWT can be seen in Figure 10c. Appendix B explains the different blocks of the VSWT model. 


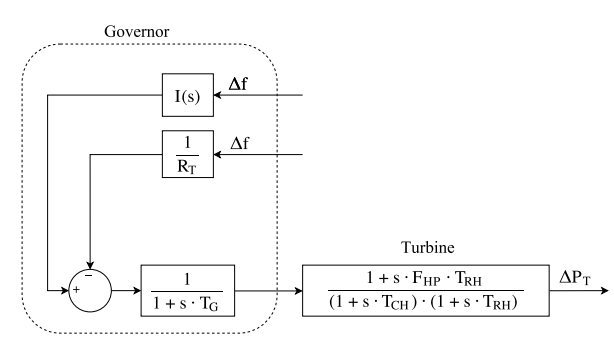

(a)

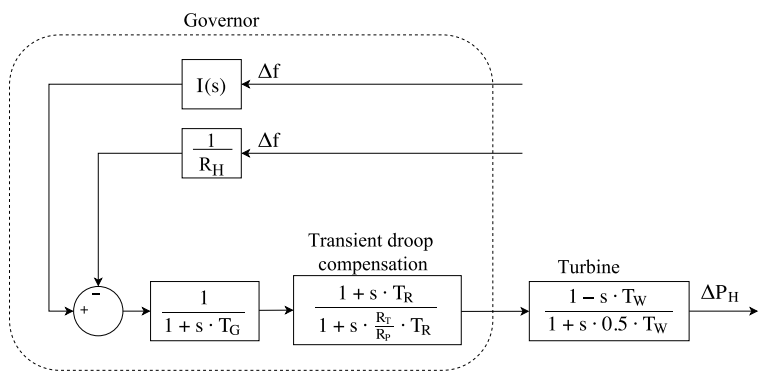

(b)

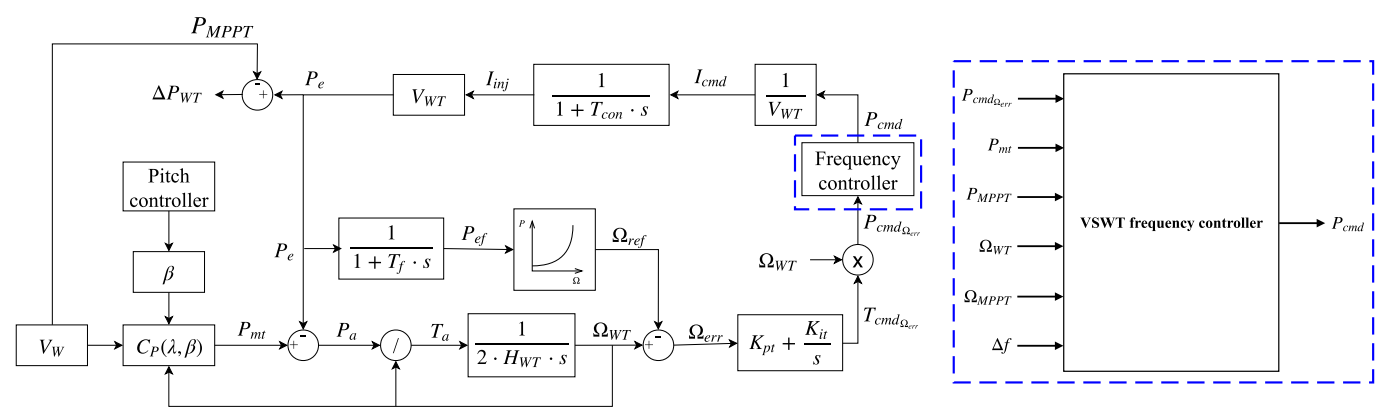

(c)

Figure 10. Power plants models. (a) Block diagram of a thermal plant model; (b) Block diagram of a hydro-power plant model; (c) Block diagrams of a VSWT model and the proposed frequency controller.

A simplified diagram in terms of variations of the power system can be seen in Figure 11, being the generated extra power $\Delta P_{g}=\Delta P_{W F}+\Delta P_{T}+\Delta P_{H}$ (the sum of the active power variation of the wind power, thermal and hydro-power plants), and $\Delta P_{L}$ the demand variation. The frequency excursion can be thus estimated from the following expression,

$$
\Delta f=\frac{1}{2 H_{e q} s+D_{e q}} \cdot\left(\Delta P_{g}-\Delta P_{L}\right),
$$

where $D_{e q}$ is the equivalent damping factor of the loads and $H_{e q}$ is the equivalent inertia constant of the system, determined as Equation (2)

$$
H_{e q}=\frac{\sum_{i=1}^{N} H_{i} \cdot S_{B, i}}{S_{B}},
$$

$H_{i}$ refers to the inertia constant of power plant $i, S_{B, i}$ is the rated power of power plant $i, S_{B}$ is the rated power of the power system and $N$ is the total number of conventional generators.

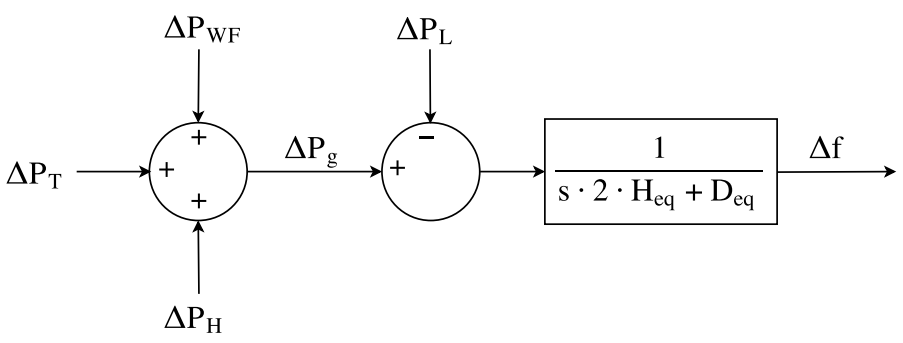

Figure 11. Simplified diagram of the modeled power system. 


\subsection{Description of the Scenarios}

Taking into account the contribution of the different sources from the supply-side in the EU-28 during 2016, see Table 1, four different scenarios have been studied. The first scenario corresponds to the current European supply-side situation, where $75 \%$ comes from thermal power plants (conventional and nuclear plants), $12 \%$ from hydro-power plants and $13 \%$ from non-manageable sources, mainly wind, and other renewables that do not provide frequency control. According to the relevant presence of wind energy, in the rest of scenarios the non-manageable sources have been considered to be just wind power plants. Moreover, the frequency controllers indicated in Section 2 (approach of [23] and the new scheme proposed in this work) have been included in the wind power plant model, keeping constant the capacity of the hydro-power plant $(12 \%)$. Both thermal and wind capacities have changed depending on the scenarios in order to simulate a power system with high integration of RES. As a consequence, the total inertia of the power system is reduced, due to the fact that VSWTs and thus wind power plants are decoupled from the grid. The considered scenarios for simulation purposes are summarized in Table 2, where $H_{e q}$ has been determined according to Equation (2). To evaluate the VSWTs frequency controller, three power imbalances $\left(\Delta P_{L, 1}=0.025\right.$, $\Delta P_{L, 2}=0.050, \Delta P_{L, 3}=0.100$ ) have been considered, resulting in 12 different scenarios.

Table 1. Contribution of sources in EU-28 in 2016 [31].

\begin{tabular}{cc}
\hline Source & Contribution (\%) \\
\hline Conventional thermal & 48.6 \\
\hline Nuclear & 25.8 \\
\hline Hydro & 12.0 \\
\hline Wind & 9.7 \\
\hline Geothermal & 0.2 \\
\hline Other & 3.7 \\
\hline
\end{tabular}

Table 2. Capacity of each generating unit and total RES integration.

\begin{tabular}{ccccc}
\hline Source & Scenario 1 & Scenario 2 & Scenario 3 & Scenario 4 \\
\hline Thermal plant & $75 \%$ & $73 \%$ & $58 \%$ & $43 \%$ \\
\hline Hydro-power plant & $12 \%$ & $12 \%$ & $12 \%$ & $12 \%$ \\
\hline Wind power plant & Others & $15 \%$ & $30 \%$ & $45 \%$ \\
\hline$H_{e q}$ & $4.15 \mathrm{~s}$ & $4.05 \mathrm{~s}$ & $3.29 \mathrm{~s}$ & $2.54 \mathrm{~s}$ \\
\hline
\end{tabular}

\section{Results}

With the aim of evaluating the suitability of the proposed VSWTs frequency controller, three different strategies have been analyzed:

1. Thermal and hydro-power plants with frequency control (without frequency response from wind power plants).

2. Thermal and hydro-power plants with frequency control and wind power plants with the frequency controller of [23].

3. Thermal and hydro-power plants with frequency control and wind power plants with the proposed frequency controller.

When wind power plants are excluded from frequency control, frequency excursions by considering the different scenarios are shown in Figure 12. As wind power integration increases, without providing frequency response, the lowest point or Nadir becomes more and more significant, 
achieving $-302 \mathrm{mHz}$ in scenario 4 considering the same value of $\Delta P_{L}$, being over 1.5 times in comparison to the first one. With regard to the stabilization time (defined as the time interval taken by the frequency deviation to be within the range $|\Delta f|<10 \mathrm{mHz}$ [32]), it enhances slightly. In scenario 4, it is 1.3 times over the first one, increasing from 28 to $34 \mathrm{~s}$. The rate of change of frequency (ROCOF) also increases with the integration of wind energy without frequency response, from $83 \mathrm{mHz} / \mathrm{s}$ in scenario 1 to $132 \mathrm{mHz} / \mathrm{s}$ in scenario 4 . Therefore, the more wind power integration into grids, the more sensitive is the power system under imbalance conditions. Subsequently, a more unstable grid results from the integration of renewables without implementing any frequency response. Similar relationships are found when $\Delta P_{L}=0.050$ and $\Delta P_{L}=0.100$ (Figure 12b,c, respectively). In Figure 13, a comparison among Nadir, stabilization time and ROCOF for the different scenarios and $\Delta P_{L}=0.050$ is depicted. Results are shown in pu, considering as base the results of scenario 1 , where there are no wind power plants.

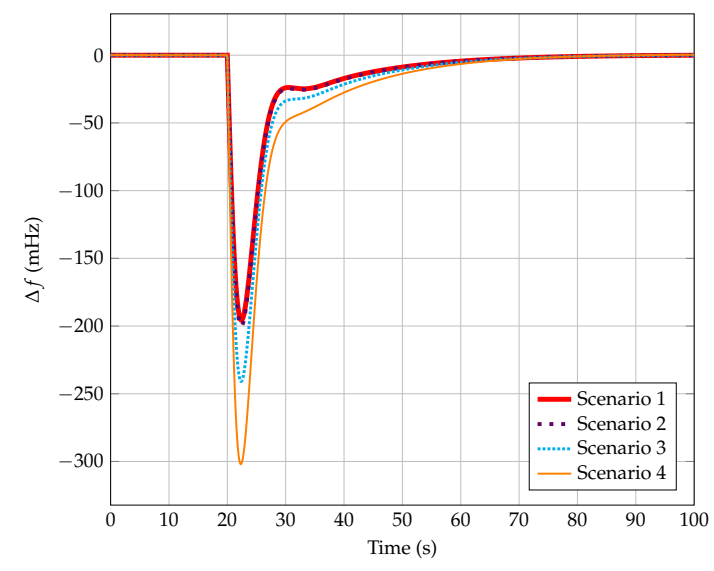

(a)

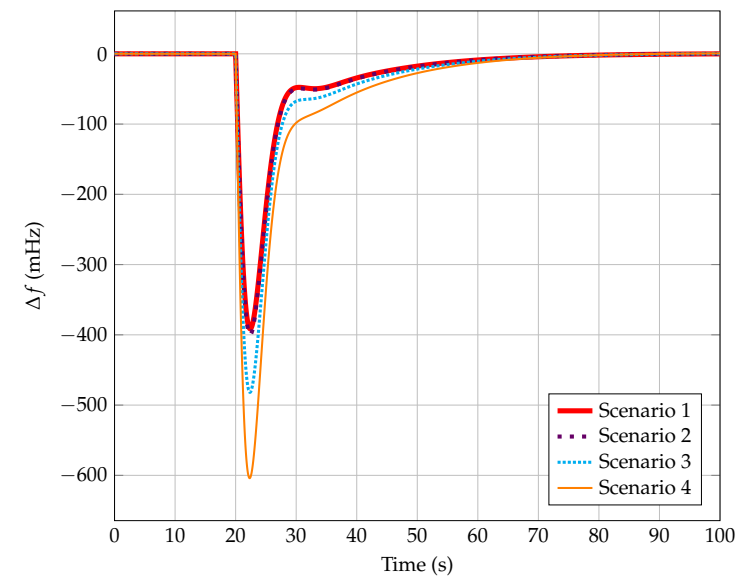

(b)

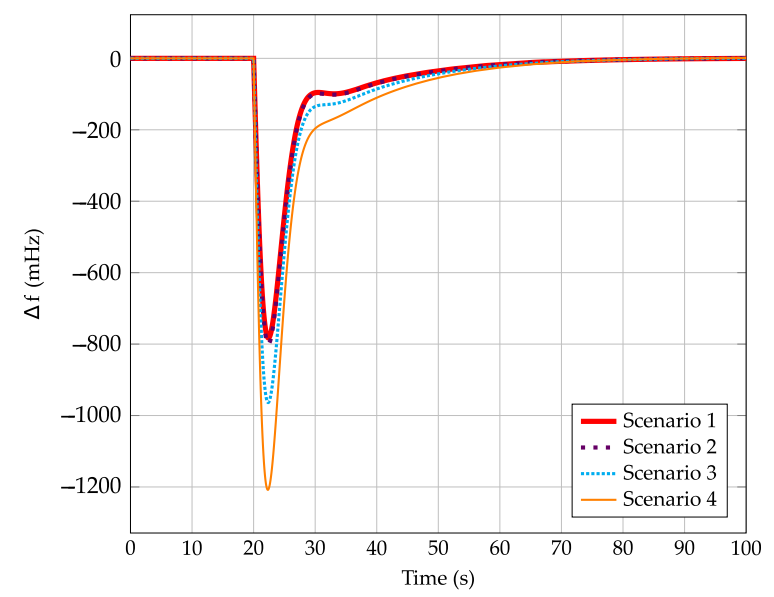

(c)

Figure 12. Frequency excursions for scenarios $1-4$ without wind power plant control. (a) Considering $\Delta P_{L}=0.025 ;(\mathbf{b})$ Considering $\Delta P_{L}=0.050 ;$ (c) Considering $\Delta P_{L}=0.100$.

To overcome previous frequency excursion drawbacks, and to determine the most suitable recovery strategy of the smooth controller proposed in this work, the four different recovery strategies are analyzed hereinafter. They are represented for the scenario 2, considering $\Delta P_{L}=0.050$ in Figure 14a and $\Delta P_{L}=0.100$ in Figure $14 \mathrm{~b}$. Due to the low value of the power of point $P_{2}$ (see Figure 7), the frequency deviation presents undesirable oscillations when the wind power plant is within the 
recovery operation mode. This effect is especially significant in the original proposal, and it is reduced as the power considers the difference between the actual mechanical power $P_{m t}\left(\Omega_{W T}\right)$ and the maximum mechanical power available according to the wind speed $P_{M P P T}\left(\Omega_{W T}\right)$. Actually, the best response is obtained when $P_{2}$ is defined as $P_{M P P T}\left(\Omega_{V}\right)+0.75 \cdot\left(P_{m t}\left(\Omega_{W T}\right)-P_{M P P T}\left(\Omega_{W T}\right)\right)$. Because of that, the rest of the results only consider that case $(x=0.75)$.

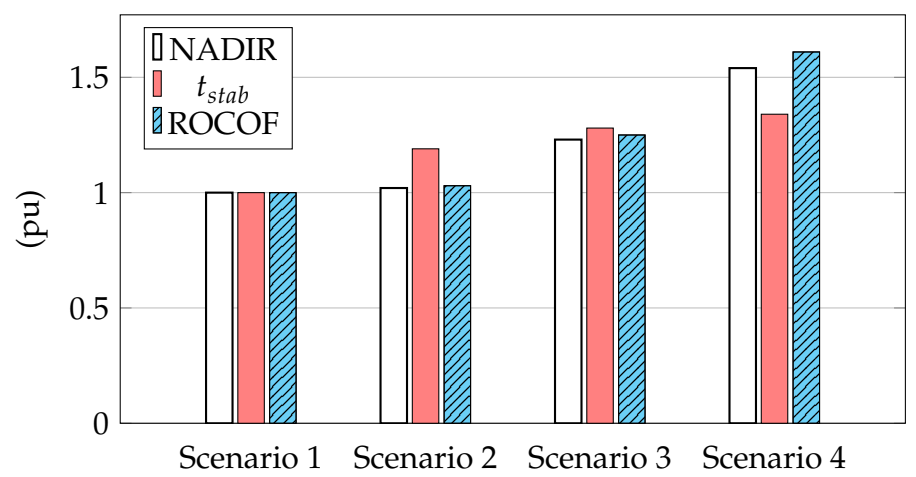

Figure 13. Nadir, stabilization time and the rate of change of frequency (ROCOF): comparison for the different scenarios without wind power plant control for $\Delta P_{L}=0.050$.

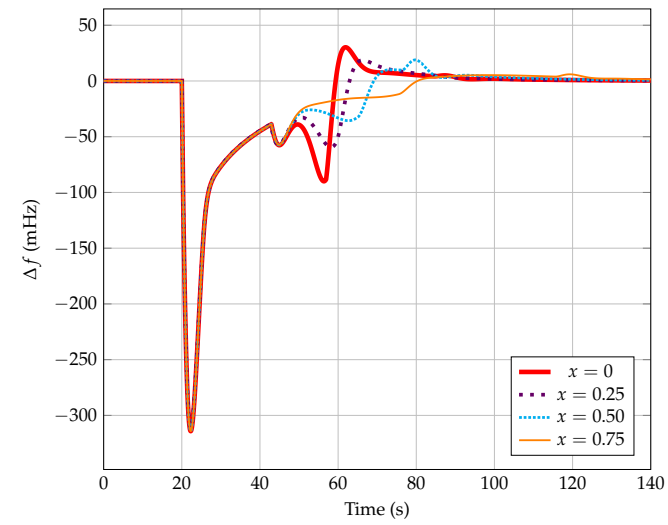

(a)

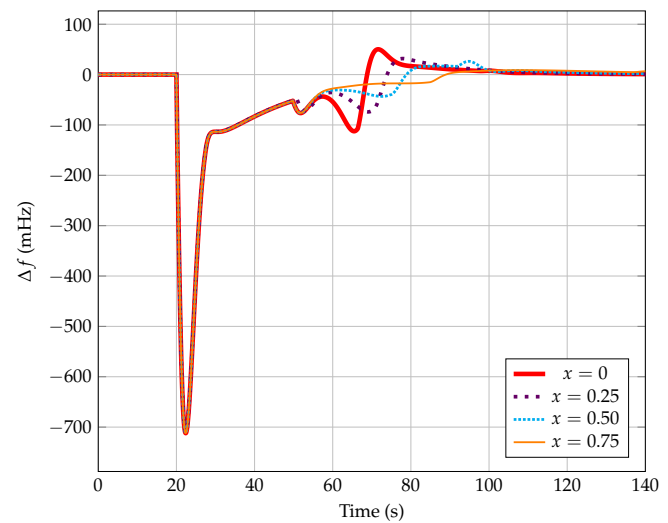

(b)

Figure 14. Frequency excursion for scenario 2. Comparison among values of $x$. (a) Considering $\Delta P_{L}=0.050 ;(\mathbf{b})$ Considering $\Delta P_{L}=0.100$.

Figures 15-17 summarize the different scenarios including frequency response from VSWTs when $\Delta P_{L}=0.025, \Delta P_{L}=0.050$ and $\Delta P_{L}=0.100$, respectively. Figures 15a, 16a and 17a refer to the controller indicated in [23]. Figures $15 \mathrm{~b}, 16 \mathrm{~b}$ and $17 \mathrm{~b}$ use the new proposal of this work, assuming $x=0.75$ in line with the previous discussion. According to the results, scenarios 2-4 present two different well-identified frequency shifts: (i) due to the power imbalance and (ii) due to the supply-side decrease as a consequence of the step from overproduction to recovery operation mode of the VSWTs frequency controller, see Figure 8. 


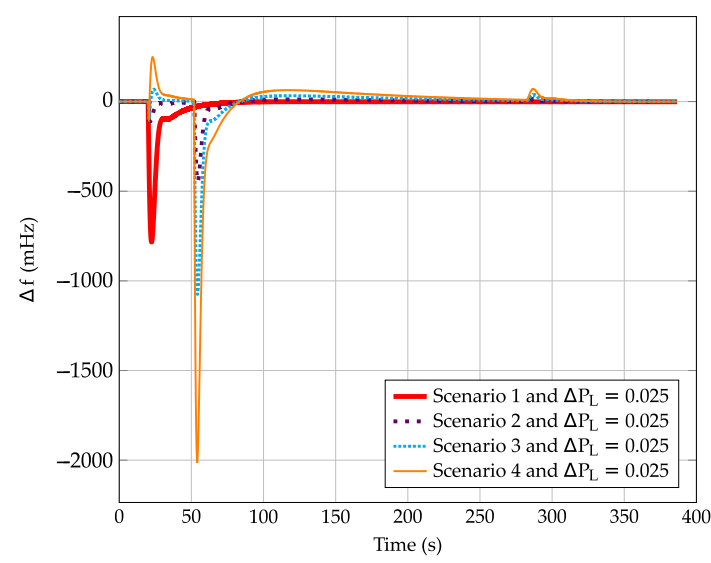

(a)

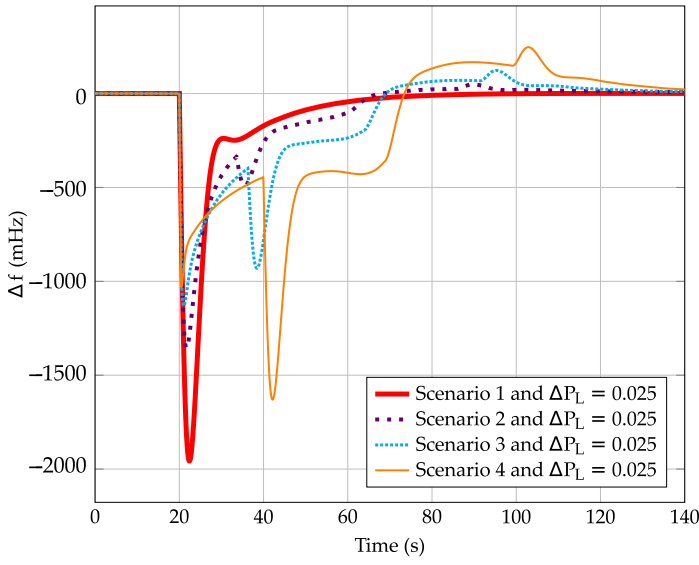

(b)

Figure 15. Comparison between frequency excursion for scenarios 1-4 including wind power plant controls and considering $\Delta P_{L}=0.025$. (a) Controller from [23]; (b) Proposed control with $x=0.75$.

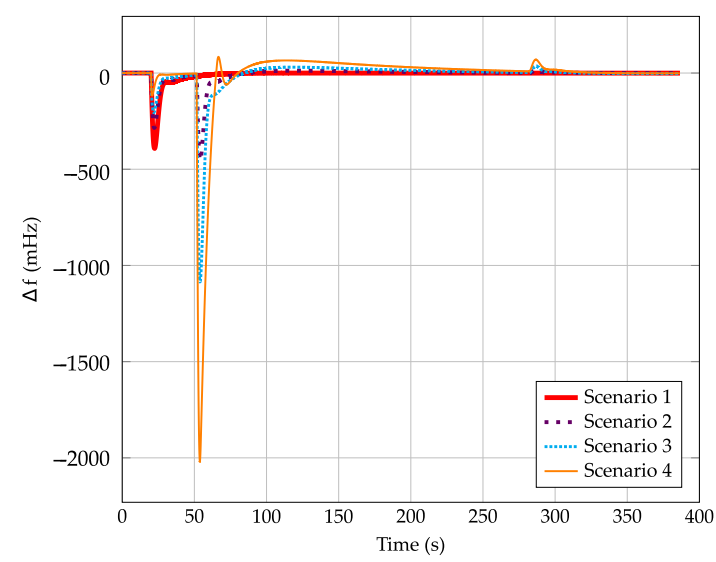

(a)

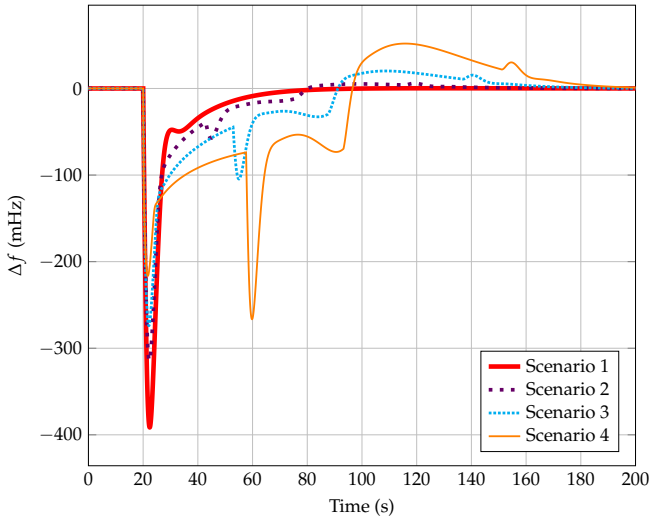

(b)

Figure 16. Comparison between frequency excursion for scenarios 1-4 including wind power plant controls and considering $\Delta P_{L}=0.050$. (a) Controller from [23]; (b) Proposed control with $x=0.75$.

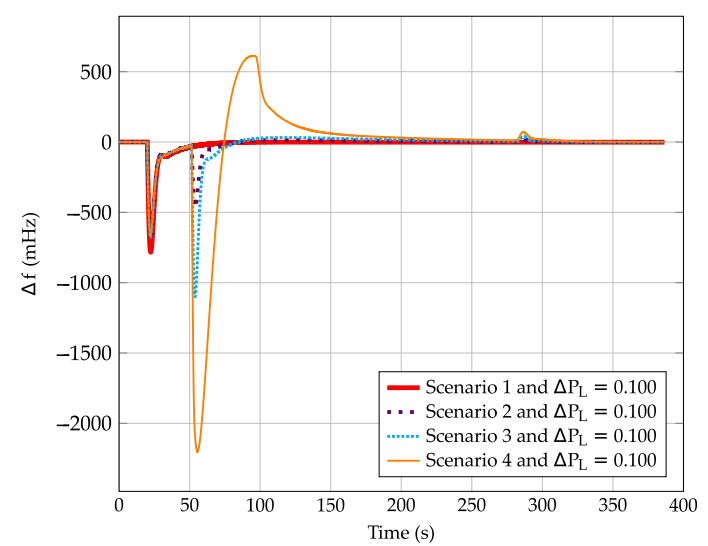

(a)

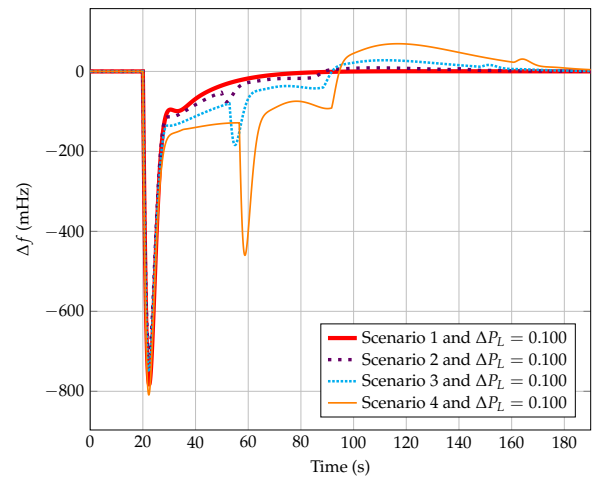

(b)

Figure 17. Comparison between frequency excursion for scenarios 1-4 including wind power plant controls and considering $\Delta P_{L}=0.100$. (a) Controller from [23]; (b) Proposed control with $x=0.75$. 
With regard to the power imbalance condition, the frequency shift decreases as the wind energy integration increases. This reduction is due to the fast support provided by VSWTs under a generation-load mismatch. It is more noticeable when the proposal of [23] is considered, as the overproduction power is constant and independent from the frequency deviation. Actually, if the demand variation is small (i.e., $\Delta P_{L}=0.025$ ), the overproduction mode of the approach indicated in [23] may cause an overfrequency instead of an underfrequency, since the additional active power definition $\Delta P_{O P}$ (see Figure 15a, scenarios 3 and 4). This drawback does not occur if the adaptive frequency controller proposed in this work is used, as seen in Figure 15b. Considering the case in which $\Delta P_{L}=0.050$, a reduction of $70 \%$ is obtained with the approach of [23], from $391 \mathrm{mHz}$ in the first scenario to 117 in the last one. This reduction accounts for the $44 \%$, reaching $215 \mathrm{mHz}$ in scenario 4 with the new controller proposal. Finally, when $\Delta P_{L}=0.100$, both frequency controllers have similar responses during the firsts seconds, reaching a Nadir $\simeq 750 \mathrm{mHz}$.

With respect to the second frequency shift, it increases with high wind power plant integration, as it increase leads to a greater wind power generation reduction when switching from overproduction to recovery. The underfrequency value can decrease to $2 \mathrm{~Hz}$ in scenario 4 with the approach indicated in [23], due to the sudden drop of generation from VSWTs, see Figure 9. Nevertheless, this second excursion is reduced using the smooth recovery proposal of this work, decreasing up to 163,266 , $450 \mathrm{mHz}$ for scenario 4 when $\Delta P_{L}=0.025, \Delta P_{L}=0.050, \Delta P_{L}=0.100$, respectively. This fact brings out that the new proposed adaptive and smoother controller gives an improvement of the frequency response, being suitable for power systems with high wind power penetration. In Figure 18, a comparison between both frequency deviations corresponding to both frequency control strategies considering $\Delta P_{L}=0.050$ are depicted.

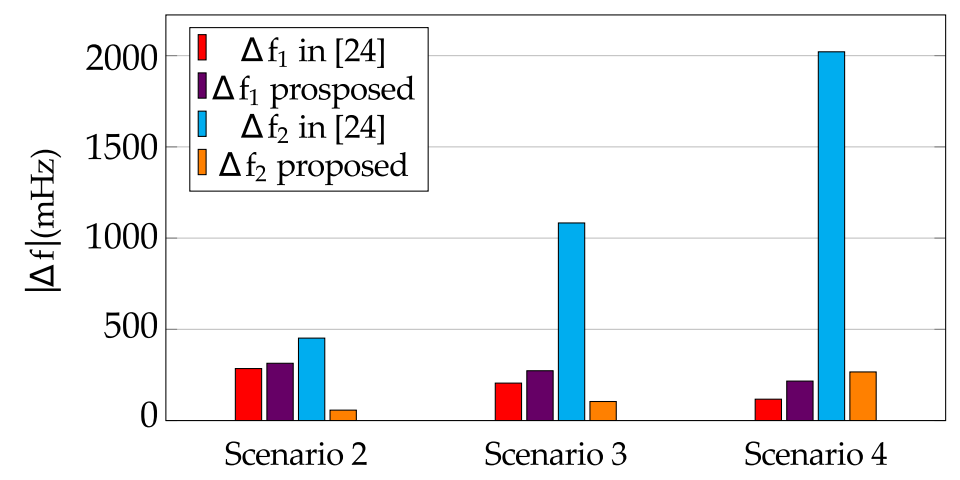

Figure 18. Comparison between $\Delta f_{1}$ and $\Delta f_{2}$ for the different scenarios depending on the wind power plant control and considering $\Delta P_{L}=0.050$.

Regarding to ROCOF, its behavior depends on the scenario and $\Delta P_{L}$. In general, it can be said that ROCOF decreases in scenarios 2 and 3, but increases in scenario 4. Actually, it is higher than the ROCOF of scenario 1 when the wind power plant frequency controller of [23] is analyzed. The stabilization time increases with the wind power plant integration, as a result of the second frequency dip. In the last scenario, the stabilization time is around $280 \mathrm{~s}$ for the control strategy indicated in [23] (independently from the value of $\Delta P_{L}$ ), varying between 80 and $140 \mathrm{~s}$ for the proposed approach. Figures 19 and 20 compare Nadir, stabilization time and Nadir for $\Delta P_{L}=0.050$. The increasing of the stabilization time in [23] is due to the fact that when the wind power plant changes from recovery to normal operation mode, a third frequency shift occurs. Despite it is not so noticeable compared to the second frequency excursion, see Figures 15a, 16a and 17a, it can achieve up to $70 \mathrm{mHz}$ for scenario 4 . 


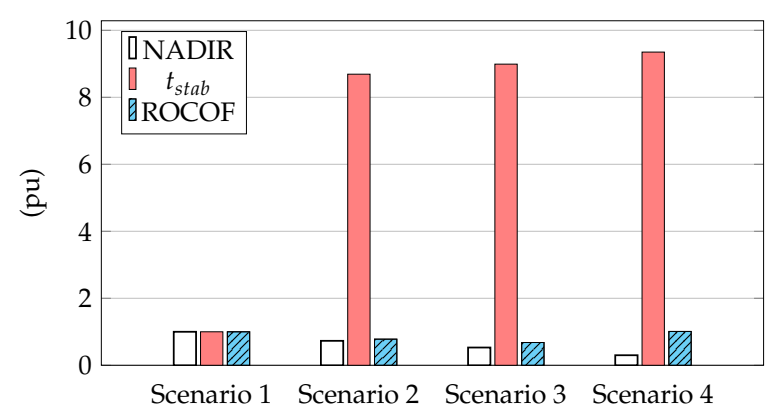

Figure 19. Nadir, stabilization time and ROCOF: comparison for the different scenarios considering $\Delta P_{L}=0.050$ and including wind power plant control from [23].

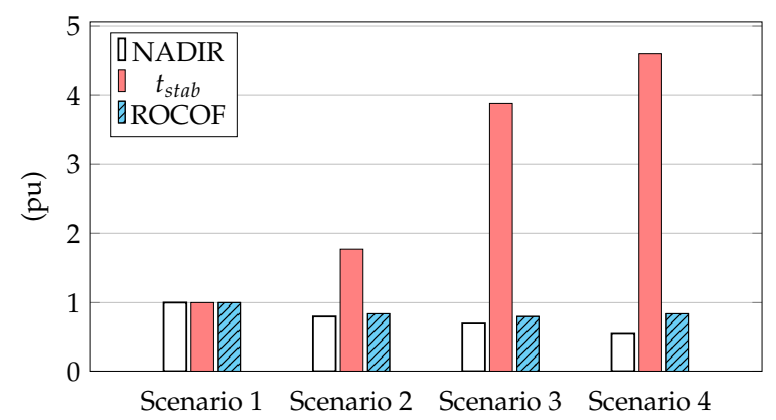

Figure 20. Nadir, stabilization time and ROCOF: comparison for the different scenarios considering $\Delta P_{L}=0.050$ and including the proposed wind power plant control.

In Figure 21 the wind power plant response of scenario 2 and $\Delta P_{L}=0.050$ with the frequency controller of [23] is depicted. Between points [1]-[2], the VSWT is working in the normal operation mode, providing its maximum power $P_{M P P T}=0.745 \mathrm{pu}$. Because of that, the variation of active power provided is 0 (see definition of $\Delta P_{W F}$ in Section 2). The rotational speed of the machine is $\Omega_{M P P T}=1.197 \mathrm{pu}$. At time $t=20 \mathrm{~s}$, the power imbalance occurs, activating the overproduction mode (points [2]-[3]). Hence, the variation of active power provided by the wind power plant is constant and equal to $\Delta P_{W F}=0.1 \mathrm{pu}$. This value corresponds to the additional active power provided by the VSWTs in this operation mode, $\Delta P_{O P}$, which is taken from the stored kinetic energy of the machine. As a consequence, the rotational speed of the VSWT decreases from $\Omega_{M P P T}=1.197$ to the minimum value $\Omega_{W T \text {, min }}=0.700 \mathrm{pu}$, corresponding to a $42 \%$ of decrease in $30 \mathrm{~s}$. When $\Omega_{W T}$ reaches its minimum value, the frequency controller changes to recovery operation mode (points [4]-[5])). The sudden drop of the variation of active power generated (points [3]-[4]) causes a second frequency departure, being this deeper than that due to the power imbalance. This power variation is $\Delta P_{W F}=P_{[4]}-P_{[3]}=-0.27-0.1=-0.37 \mathrm{pu}$. Apart from that, it is important to notice that it takes around $250 \mathrm{~s}$ to restore the rotational speed to the initial value $\Omega_{M P P T}$.

Regarding to Figure 22, the wind power plant response of scenario 2 and $\Delta P_{L}=0.050$ with the proposed controller considering $x=0.75$ is shown. In this case, the rotational speed decreases from 1.197 to $1.117 \mathrm{pu}$ in $20 \mathrm{~s}$ (points [2]-[3]). Despite it takes less time than in Figure 21, the reduction of rotational speed is also lower, only $0.07 \%$. Furthermore, the second frequency departure caused by the drop from overproduction to recovery (points [3]-[4]: $\Delta P_{W F}=P_{[4]}-P_{[3]}=-0.015-0.075=-0.090 \mathrm{pu}$ ) is negligible in comparison to the one indicated in Figure 21. The wind power plant needs only $80 \mathrm{~s}$ to restore the rotational speed to the initial value (points [4]-[5]). The equation of the parabola in this case is: $P_{c m d}=19.06 \cdot \Omega_{W T}^{2}-43.93 \cdot \Omega_{W T}+26.02$. 


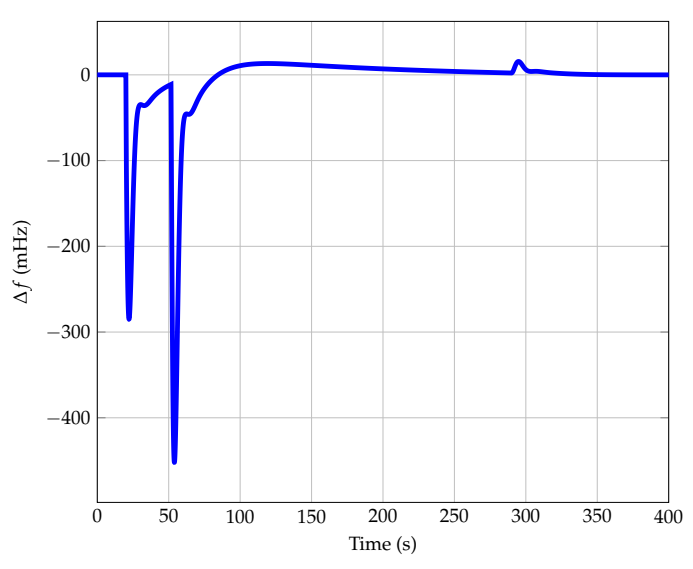

(a)

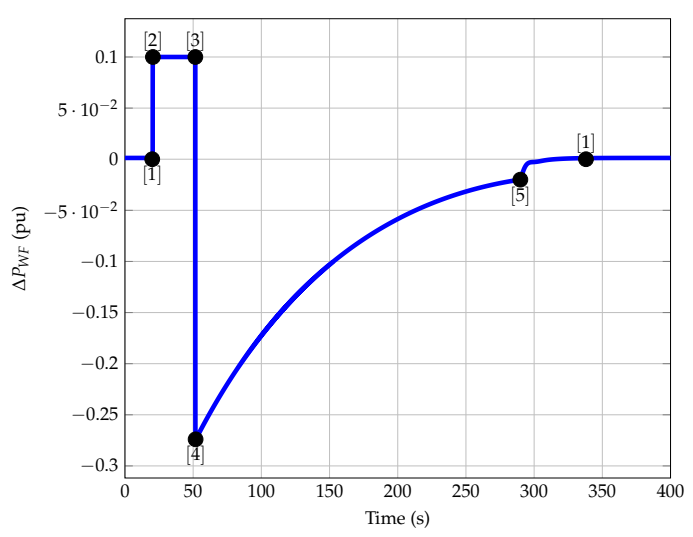

(c)

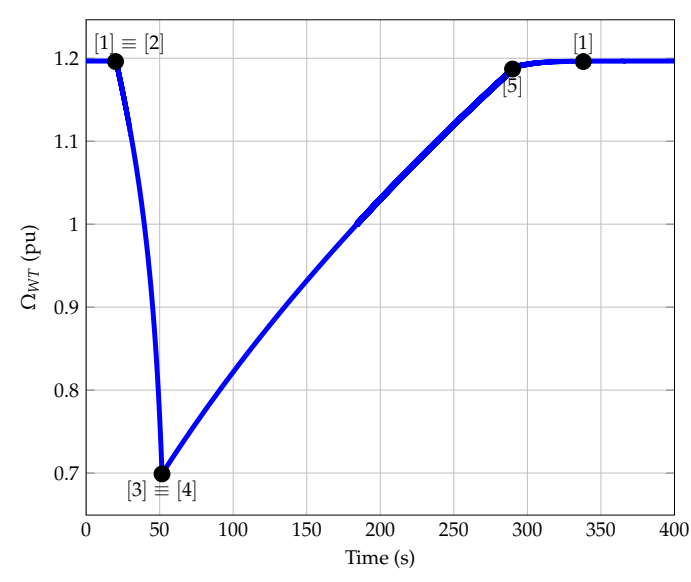

(b)

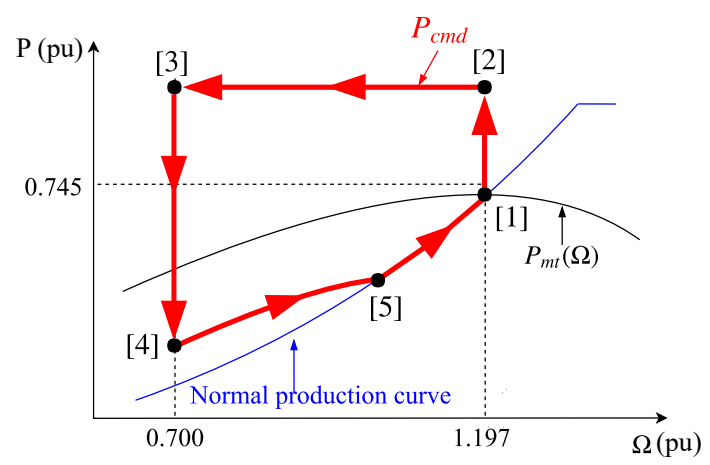

(d)

Figure 21. Wind power plant response for scenario 2 and frequency controller of [23]. (a) Frequency deviation; (b) Rotational speed; (c) Variation of wind power; (d) Frequency control strategy.

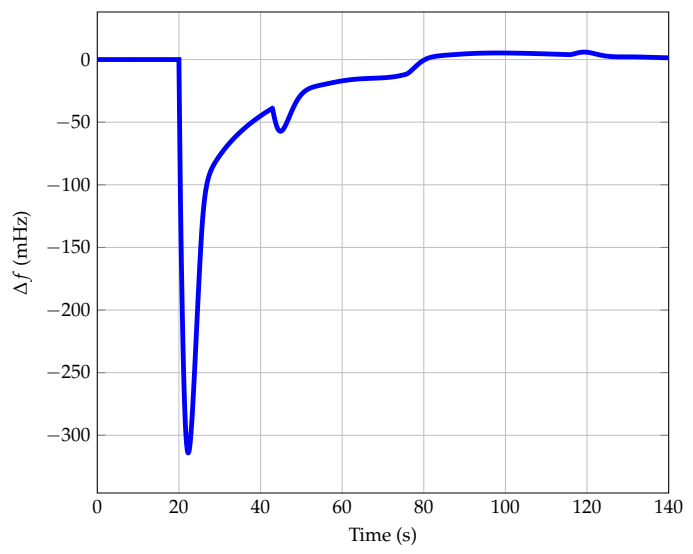

(a)

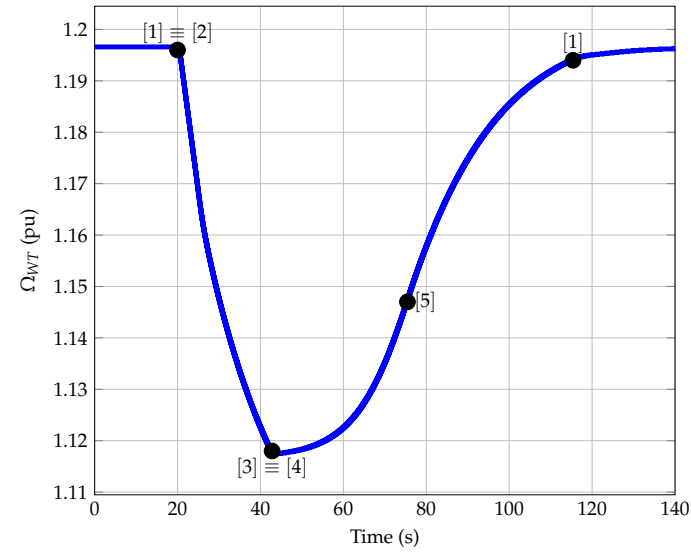

(b)

Figure 22. Cont. 


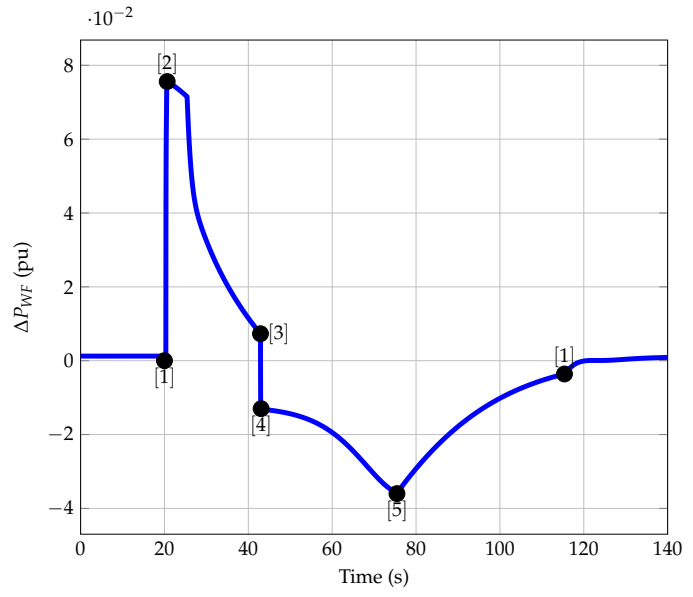

(c)

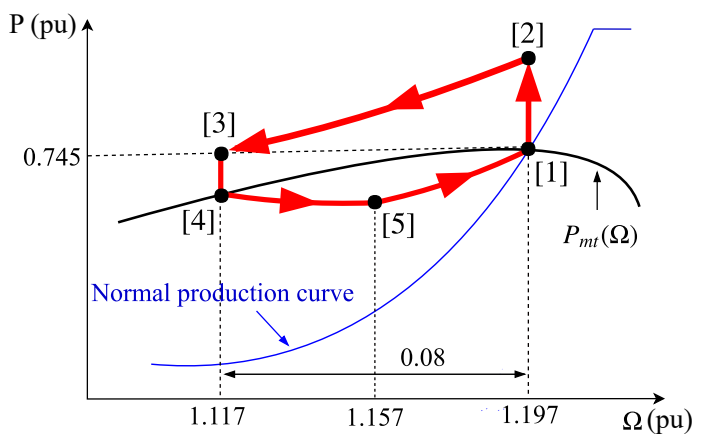

(d)

Figure 22. Wind power plant response for scenario 2 and adaptive and smoother frequency controller with $x=0.75$. (a) Frequency deviation; (b) Rotational speed; (c) Variation of wind power; (d) Frequency control strategy.

\section{Conclusions}

A new control for VSWTs has been proposed in order to allow them to participate in frequency control. It is based on two operation modes: overproduction and recovery, varying the active power provided by the VSWTs through the 'hidden' kinetic inertia stored in their rotating masses. It is tested within four different supply-side scenarios consisting of thermal, hydro-power and wind power plants. In each scenario, wind power plants have increased their capacity from 15 to $45 \%$, at the time that thermal plants have decreased from 73 to $43 \%$ in order to estimate the frequency response of a future power system with high integration of renewable energy sources.

Results show that the Nadir can be reduced a $45 \%$ if the wind power plant control proposed participates in frequency control, compared to current situations in which only conventional plants provide frequency control. A secondary frequency dip is identified due to the change from overproduction to recovery periods, consequently increasing the stabilization time. Results are also compared to a previous proposal, improving Nadir, stabilization time and especially the secondary frequency excursion. Actually, it is due to the lack of coordination between power plants, as well as the different time response of the supply-side operation units. New aggregated and coordinated strategies are being analyzed by the authors to minimize the impact of these secondary deviations.

Author Contributions: All authors contributed equally to this work.

Acknowledgments: This work was supported by "Fundación Séneca-Agencia de Ciencia y Tecnología de la Región de Murcia" (ref. 19379/PI/14) and "Ministerio de Educación, Cultura y Deporte" of Spain (ref. FPU16/04282).

Conflicts of Interest: The authors declare no conflict of interest.

\section{Abbreviations}

The following abbreviations are used in this manuscript:

a First parameter of the parabola

$b \quad$ Second parameter of the parabola

c Third parameter of the parabola

$n \quad$ Number of VSWT in the wind power plant

$C_{P} \quad$ Power coefficient

$D_{e q} \quad$ Equivalent damping factor of the power system 
$H_{e q} \quad$ Equivalent inertia constant of the power system

$H_{i} \quad$ Inertia constant of each generator unit

$P_{\text {acc }} \quad$ Acceleration power

$P_{c m d} \quad$ Commanded power of the VSWT

$P_{e} \quad$ Active power provided by the wind power plant

$P_{e f} \quad$ Active measured power provided by the wind power plant

$P_{\text {MPPT }} \quad$ Maximum power point tracking of the VSWT

$P_{m t} \quad$ Mechanical power of the VSWT

$P_{1} \quad$ First point to calculate the parabola: $P_{1}:\left(\Omega_{W T, \min }, P_{m t}\left(\Omega_{W T, \min }\right)\right)$

$P_{2} \quad$ Second point to calculate the parabola: $P_{2}:\left(\Omega_{V}, P_{M P P T}\left(\Omega_{V}\right)\right)$

$P_{3} \quad$ Third point point to calculate the parabola: $P_{3}:\left(\Omega_{M P P T}, P_{M P P T}\left(\Omega_{M P P T}\right)\right)$

$S_{B} \quad$ Rated power of the power system

$S_{B, i} \quad$ Rated power of each power generation unit

$V_{W} \quad$ Wind speed

$\beta \quad$ Pitch angle

$\Delta f \quad$ Frequency excursion

$\Delta f_{\text {lim }} \quad$ Value at which frequency controller of the VSWT activates

$\Delta P_{g} \quad$ Variation of active power of the power system: $\Delta P_{g}=\Delta P_{W F}+\Delta P_{T}+\Delta P_{H}$

$\Delta P_{H} \quad$ Variation of active power of the hydro-power plant

$\triangle P_{L} \quad$ Variation of power demand

$\triangle P_{O P} \quad$ Additional active power in overproduction operation mode

$\Delta P_{T} \quad$ Variation of active power of the thermal plant

$\Delta P_{W F} \quad$ Variation of active power of the wind power plant

$\Delta \Omega \quad$ Rotational speed deviation: $\Delta \Omega=\Omega_{M P P T}-\Omega_{W T, \min }$

$\lambda \quad$ Tip speed ratio

$\Omega_{\text {err }} \quad$ Rotational speed error: $\Omega_{e r r}=\Omega_{W T}-\Omega_{\text {ref }}$

$\Omega_{W T} \quad$ Rotational speed of the VSWT

$\Omega_{W T, \text { min }}$ Minimum rotational speed of the VSWT

$\Omega_{M P P T} \quad$ Rotational speed at maximum power point tracking

$\Omega_{\text {ref }} \quad$ Rotational reference speed

$\Omega_{V} \quad$ Middle value between $\Omega_{W T, \min }$ and $\Omega_{M P P T}: \Omega_{V}=\Omega_{W T, \min }+0.5 \cdot \Delta \Omega$

\section{Appendix A. Parameters for Simulations}

Tables A1 and A2 summarize the thermal and hydro-power plant parameters.

Table A1. Thermal power plant parameters [26].

\begin{tabular}{ccc}
\hline Parameter & Name & Value $\left(\mathbf{p u} \mathbf{u}_{\text {thermal }}\right)$ \\
\hline$T_{G}$ & Speed relay pilot valve & 0.20 \\
\hline$F_{H P}$ & Fraction of power generated by high pressure section & 0.30 \\
\hline$T_{R H}$ & Time constant of reheater & 7.00 \\
\hline$T_{C H}$ & Time constant of main inlet volumes and steam chest & 0.30 \\
\hline$R_{T}$ & Speed droop & 0.05 \\
\hline$I(s)$ & Integral controller & 1.00 \\
\hline$H_{\text {thermal }}$ & Inertia constant & $5.00 \mathrm{~s}$ \\
\hline
\end{tabular}


Table A2. Hydro-power plant parameters [26].

\begin{tabular}{ccc}
\hline Parameter & Name & Value $\left(\mathbf{p u}_{\mathbf{h y d r o}}\right)$ \\
\hline$T_{G}$ & Speed relay pilot valve & 0.20 \\
\hline$T_{R}$ & Reset time & 5.00 \\
\hline$R_{T}$ & Temporary droop & 0.38 \\
\hline$R_{P}$ & Permanent droop & 0.05 \\
\hline$T_{W}$ & Water starting time & 1.00 \\
\hline$R_{H}$ & Speed droop & 0.05 \\
\hline$I(s)$ & Integral controller & 1.00 \\
\hline$H_{\text {hydro }}$ & Inertia constant & $3.00 \mathrm{~s}$ \\
\hline
\end{tabular}

\section{Appendix B. Wind Turbine Model}

The wind turbine model is based on [29,30]. Parameters of the wind turbine model are summarized in Table A4 The mechanical power $P_{m t}$ is obtained (in pu) from

$$
P_{m t}=\frac{0.5}{S_{n}} \cdot C_{P} \cdot \rho \cdot A_{r} \cdot V_{W^{\prime}}^{3}
$$

being $S_{n}$ the rated power, $\rho$ the air density, $A_{r}$ the swept area by the blades, $C_{P}$ the power coefficient and $V_{W}$ the wind speed. The power coefficient $C_{P}$ is estimated by

$$
C_{P}(\lambda, \beta)=\sum_{i=0}^{4} \sum_{j=0}^{4} \alpha_{i, j} \beta^{i} \lambda^{j}
$$

This expression gives the mathematical representation of the $C_{P}$ curves, depending on the pitch angle $\beta$ and the tip speed ratio $\lambda$,

$$
\lambda=\frac{\Omega_{0} \cdot R \cdot \Omega_{W T}}{V_{W}}
$$

where $\Omega_{0}$ is the rotor base speed ( $\left.\mathrm{rad} / \mathrm{s}\right), \Omega_{W T}$ refers to the rotor speed (pu), $R$ is the rotor radius (m) and $V_{W}$ is the wind speed $(\mathrm{m} / \mathrm{s})$. Coefficients of $\alpha_{i, j}$ are taken from Table A3.

Table A3. Coefficients $\alpha_{i, j}$ to calculate $C_{P}(\lambda, \beta)$

\begin{tabular}{cccccc}
\hline $\mathbf{i j}$ & $\mathbf{0}$ & $\mathbf{1}$ & $\mathbf{2}$ & $\mathbf{3}$ & $\mathbf{4}$ \\
\hline $\mathbf{0}$ & $-4.19 \cdot 10^{-1}$ & $2.18 \cdot 10^{-1}$ & $-1.24 \cdot 10^{-2}$ & $-1.34 \cdot 10^{-4}$ & $1.15 \cdot 10^{-5}$ \\
\hline $\mathbf{1}$ & $-6.76 \cdot 10^{-2}$ & $6.04 \cdot 10^{-2}$ & $-1.39 \cdot 10^{-2}$ & $1.07 \cdot 10^{-3}$ & $-2.39 \cdot 10^{-5}$ \\
\hline $\mathbf{2}$ & $1.57 \cdot 10^{-2}$ & $-1.01 \cdot 10^{-2}$ & $2.15 \cdot 10^{-3}$ & $-1.49 \cdot 10^{-4}$ & $2.79 \cdot 10^{-6}$ \\
\hline $\mathbf{3}$ & $-8.60 \cdot 10^{-4}$ & $5.71 \cdot 10^{-4}$ & $-1.05 \cdot 10^{-4}$ & $5.99 \cdot 10^{-6}$ & $-8.91 \cdot 10^{-8}$ \\
\hline $\mathbf{4}$ & $1.48 \cdot 10^{-5}$ & $-9.48 \cdot 10^{-6}$ & $1.62 \cdot 10^{-6}$ & $-7.15 \cdot 10^{-8}$ & $4.97 \cdot 10^{-10}$ \\
\hline
\end{tabular}

The reference rotational speed $\Omega_{r e f}$ is estimated from the maximum power tracking based on the measured active power $P_{e f}$

$$
\Omega_{r e f}=-0.67 \cdot P_{e f}^{2}+1.42 \cdot P_{e f}+0.51,
$$

being $P_{e f}$ the active power generated $P_{e}$ after a delay $T_{f}$. 
The rotational speed of the wind turbine $\Omega_{W T}$ is determined from

$$
\Omega_{W T}(s)=\frac{P_{e}(s)-P_{m t}(s)}{2 H_{W T} \cdot s}
$$

being $H_{W T}$ the inertia constant of the wind turbine. The speed controller is modeled as a PI controller, based on the rotational speed error $\Omega_{\text {err }}$

$$
T_{c m d_{\Omega_{e r r}}}=\left(K_{p t}+\frac{K_{i t}}{s}\right) \Omega_{e r r}
$$

Table A4. Wind power plant parameters [29].

\begin{tabular}{ccc}
\hline Parameter & Name & Value $(\mathbf{p u} \mathbf{W F})$ \\
\hline$V_{w}$ & Wind speed & $10.000 \mathrm{~m} / \mathrm{s}$ \\
\hline$H_{W T}$ & Inertia constant & $5.190 \mathrm{~s}$ \\
\hline$\Omega_{0}$ & Base rotational speed & $1.335 \mathrm{rad} / \mathrm{s}$ \\
\hline$T_{f}$ & Time delay to measure $P_{e}$ & $5.000 \mathrm{~s}$ \\
\hline$T_{c o n}$ & Time delay to generate the current $I_{i n j}$ & $0.020 \mathrm{~s}$ \\
\hline$V_{W T}$ & Wind turbine voltage & 1.00 \\
\hline$K_{p t}$ & Proportional constant of speed controller & 3.000 \\
\hline$K_{i t}$ & Integral constant of speed controller & 0.600 \\
\hline
\end{tabular}

\section{References}

1. Huber, M.; Dimkova, D.; Hamacher, T. Integration of wind and solar power in Europe: Assessment of flexibility requirements. Energy 2014, 69, 236-246. [CrossRef]

2. Tselepis, S.; Nikoletatos, J. Renewable Energy Integration in Power Grids; The International Renewable Energy Agency: Masdar City, United Arab Emirates, 2015.

3. Bevrani, A.G.H.; Ledwich, G. Renewable energy sources and frequency regulation: Survey and new perspectives. IET Renew. Power Gener. 2010, 4, 438-457. [CrossRef]

4. Bahrami, S.; Amini, M.H. A decentralized trading algorithm for an electricity market with generation uncertainty. Appl. Energy 2018, 218, 520-532. [CrossRef]

5. Zhang, W.; Fang, K. Controlling active power of wind farms to participate in load frequency control of power systems. IET Gener. Transm. Distrib. 2017, 11, 2194-2203. [CrossRef]

6. Shah, R.; Mithulananthan, N.; Bansal, R.; Ramachandaramurthy, V. A review of key power system stability challenges for large-scale PV integration. Renew. Sustain. Energy Rev. 2015, 41, 1423-1436. [CrossRef]

7. Du, P.; Matevosyan, J. Forecast system inertia condition and its impact to integrate more renewables. IEEE Trans. Smart Grid 2018, 9, 1531-1533. [CrossRef]

8. Li, D.Y.; Li, P.; Cai, W.C.; Song, Y.D.; Chen, H.J. Adaptive Fault Tolerant Control of Wind Turbines with Guaranteed Transient Performance Considering Active Power Control of Wind Farms. IEEE Trans. Ind. Electron. 2017, 65, 3275-3285. [CrossRef]

9. Bao, Y.; Xu, J.; Liao, S.; Sun, Y.; Li, X.; Jiang, Y.; Ke, D.; Yang, J.; Peng, X. Field Verification of Frequency Control by Energy-Intensive Loads for Isolated Power Systems with High Penetration of Wind Power. IEEE Trans. Power Syst. 2018, 1. [CrossRef]

10. Toulabi, M.; Bahrami, S.; Ranjbar, A.M. An Input-to-State Stability Approach to Inertial Frequency Response Analysis of Doubly-Fed Induction Generator-Based Wind Turbines. IEEE Trans. Energy Convers. 2017, 32, 1418-1431. [CrossRef] 
11. Ochoa, D.; Martinez, S. Proposals for Enhancing Frequency Control in Weak and Isolated Power Systems: Application to the Wind-Diesel Power System of San Cristobal Island-Ecuador. Energies 2018, 11, 910. [CrossRef]

12. Aho, J.; Buckspan, A.; Laks, J.; Fleming, P.; Jeong, Y.; Dunne, F.; Churchfield, M.; Pao, L.; Johnson, K. A tutorial of wind turbine control for supporting grid frequency through active power control. In Proceedings of the 2012 American Control Conference (ACC), Montreal, QC, Canada, 27-29 June 2012; pp. 3120-3131. [CrossRef]

13. Kayikçi, M.; Milanovic, J.V. Dynamic contribution of DFIG-based wind plants to system frequency disturbances. IEEE Trans. Power Syst. 2009, 24, 859-867. [CrossRef]

14. Toulabi, M.; Bahrami, S.; Ranjbar, A.M. Application of Edge theorem for robust stability analysis of a power system with participating wind power plants in automatic generation control task. IET Renew. Power Gener. 2017, 11, 1049-1057. [CrossRef]

15. Yingcheng, X.; Nengling, T. Review of contribution to frequency control through variable speed wind turbine. Renew. Energy 2011, 36, 1671-1677. [CrossRef]

16. Sun, D.; Sun, L.; Wu, F.; Zu, G. Frequency Inertia Response Control of SCESS-DFIG under Fluctuating Wind Speeds Based on Extended State Observers. Energies 2018, 11, 830. [CrossRef]

17. Tavakoli, M.; Pouresmaeil, E.; Adabi, J.; Godina, R.; Catalao, J.P. Load-frequency control in a multi-source power system connected to wind farms through multi terminal HVDC systems. Comput. Oper. Res. 2018, 96, 305-315. [CrossRef]

18. Alsharafi, A.S.; Besheer, A.H.; Emara, H.M. Primary Frequency Response Enhancement for Future Low Inertia Power Systems Using Hybrid Control Technique. Energies 2018, 11, 699. [CrossRef]

19. El Itani, S.; Annakkage, U.D.; Joos, G. Short-term frequency support utilizing inertial response of DFIG wind turbines. In Proceedings of the 2011 IEEE Power and Energy Society General Meeting, San Diego, CA, USA, 24-29 July 2011; pp. 1-8.

20. Keung, P.K.; Li, P.; Banakar, H.; Ooi, B.T. Kinetic energy of wind-turbine generators for system frequency support. IEEE Trans. Power Syst. 2009, 24, 279-287. [CrossRef]

21. Hansen, A.D.; Altin, M.; Margaris, I.D.; Iov, F.; Tarnowski, G.C. Analysis of the short-term overproduction capability of variable speed wind turbines. Renew. Energy 2014, 68, 326-336. [CrossRef]

22. Hafiz, F.; Abdennour, A. Optimal use of kinetic energy for the inertial support from variable speed wind turbines. Renew. Energy 2015, 80, 629-643. [CrossRef]

23. Tarnowski, G.C.; Kjar, P.C.; Sorensen, P.E.; Ostergaard, J. Variable speed wind turbines capability for temporary over-production. In Proceedings of the 2009 IEEE Power \& Energy Society General Meeting, Calgary, AB, Canada, 26-30 July 2009; pp. 1-7.

24. Kang, M.; Kim, K.; Muljadi, E.; Park, J.W.; Kang, Y.C. Frequency control support of a doubly-fed induction generator based on the torque limit. IEEE Trans. Power Syst. 2016, 31, 4575-4583. [CrossRef]

25. Tielens, P.; Hertem, D.V. Receding Horizon Control of Wind Power to Provide Frequency Regulation. IEEE Trans. Power Syst. 2017, 32, 2663-2672. [CrossRef]

26. Kundur, P.; Balu, N.J.; Lauby, M.G. Power System Stability and Control; McGraw-hill: New York, NY, USA, 1994; Volume 7.

27. Margaris, I.D.; Papathanassiou, S.A.; Hatziargyriou, N.D.; Hansen, A.D.; Sorensen, P. Frequency control in autonomous power systems with high wind power penetration. IEEE Trans. Sustain. Energy 2012, 3, 189-199. [CrossRef]

28. Pyller, M.; Achilles, S. Aggregated Wind Park Models for Analyzing Power System Dynamics. In Proceedings of the 4th International Workshop on Large-Scale Integration of Wind Power and Transmission Networks for Offshore Wind Farms, Billund, Denmark, 20-21 October 2003.

29. Ullah, N.R.; Thiringer, T.; Karlsson, D. Temporary primary frequency control support by variable speed wind turbines-Potential and applications. IEEE Trans. Power Syst. 2008, 23, 601-612. [CrossRef]

30. Miller, N.W.; Sanchez-Gasca, J.J.; Price, W.W.; Delmerico, R.W. Dynamic modeling of GE 1.5 and 3.6 MW wind turbine-generators for stability simulations. In Proceedings of the 2003 IEEE Power Engineering Society General Meeting (IEEE Cat. No.03CH37491), Toronto, ON, Canada, 13-17 July 2003; Volume 3, pp. 1977-1983. 
31. Electricity Statistics 2016 (in GWh). 2017. Available online: http://ec.europa.eu/eurostat/statisticsexplained/index.php/File:Electricity_Statistics_2016_(in_GWh)-T1.png (accessed on 1 June 2018).

32. ENTSOE. Network Code on Load-Frequency Control and Reserves. 2013. Available online: https:/ / www.entsoe.eu/ (accessed on 1 June 2018).

(C) 2018 by the authors. Licensee MDPI, Basel, Switzerland. This article is an open access article distributed under the terms and conditions of the Creative Commons Attribution (CC BY) license (http:/ / creativecommons.org/licenses/by/4.0/). 